THE TREATMENT

of

GENERAL PARAIYSIS OF THE INSANE.

By Dr. Robert Iees, M.B., Ch.B., F.R.C.P. (Edin.)

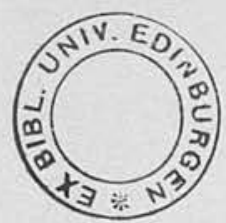




\section{TABIE OF CONTENTS.}

\section{$\underline{\text { Page. }}$}

History of General Paralysis

$$
\text { of the Insane. }
$$

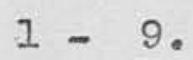

Early Diagnosis of General

Paralysis of the Insane.

$10-15$

Diagnosis of Juverille General

Paralysis of the Insane.

$15-20$.

Serological and Cerebro-spinal

Fluid Changes in General

Paralysis of the Insane.

$20-27$.

History of Fever Therapy of

Insanity.

$28-32$.

MALARIA THERAPY.

Technique of :-

Mode of Action of:-

His tological Changes after:-

$32-51$.

$51-54$.

$55-57$.

Physical Methods of Pyrexial

Trea tment.

$58-64$.

Chemo-Therapy of General Paralysis

of the Insane.

$65-67$.

REPORT ON CASES PERSONALLY TREA TED.

$68-74$.

Clinical Results.

Serological Results.

Juvenile ceneral Paralysis

$$
\text { of the Insane. }
$$

$74-81$.

$81-84$.

$84-85$.

SUMMARY AND CONCLUSIONS.

$85-87$ 
HISTORICA I.

As the history of the discovery of General paralysis is now well known, and has been admirably related by many authors, it is now only possible to add to the latest chapters of this interesting page of medical history.

G. M. Robertson (1), and Sir Hubert Bond (2) have related with great clarity and detail the steps of the evolution of medical opinion regarding this disease.

Certain early writers have commented on the association of mental disorder and subsequent Paralysis. Thomas Willis (3) "De Anima Brutorum" London, 1672, notes the sequence of mental dullness, loss of memory and finally dementia "there afterwards follows paralysis, either general paralysis (paralysis universalis) or hemiplegia, or some particular local paralysis."

The first clear description of the disease now known as General paralysis appears in 1798 John Haslam (4) writing in 1798 , notes the association of paralysis and insanity, the association of / 


\section{2.}

of extreme feebleness of body with feelings of well-being, of elation and of pride, also he recognises the gravity of the prognosis. He gives his opinion of the pathology - "it may be inferred that madness has always been connected with disease of the brain and of its membranes." -

In 1804 Cox (5) observed the serious import of paralysis in insanity. He also anticipated Argyll Robertson"s (6) later description of the pupil insensitive to light. "In a few instances, I have observed the retina almost insensitive when no other symptom of anaesthesia was present; and on submitting the pupils to a similar degree of light they have contracted unequally. These are rare but ominous occurrences and a lways render the prognosis unfavourable."

In France the problem of paralysis and insanity was being studied actively and from different angles by many workers, including Plnel and Esquirol; later Goorget (7) in his book "De la Folie" outlined the clinical stages of the disease, and finally Bayle (8) in 1822 described the morbid anatomy and correlates it with / 
with the clinical symptoms and signs. He first described the disease as "Chronic Arachnitis", but three years later changed the title to "Chronic Meningitis". He gives a very full and accurate account of the postmortem findings. In 1826 he published a full exposition of the new diserse (9), and at the same time calmeil (10) produced his work on the same lines.

The next contribution of note was by Pritchard (11) in 1835, who noted that general paralysis was often preceeded by a form of exaltation and joyous delirium, and that weakness of memory and intellect were among the first signs of the disease. At this time the disease was thought to be much more uncommon in Britain than in France; probably its incidence was not fully realised in Britain.

So far there is no mention of syphilis or venereal disease as a cause, yet Pritchard mentions the very much higher incidence in males than in females, the high incidence among prostitutes and soldiers; the influence of excess "in Baccho et venere", and also he believes that there is a natural predisposition, either inherited / 
inherited or original.

"A Manual of Psychological Medicine" published in 1858 by Buckmill \& Tuke (12) contains a section devoted to the diagnosis of General Paralysis of the Insane. They endorse the view then held that General Paralysis "is essentially a disease of nutrition affecting the whole of the nervous system." At this time also microscopic examination of the brain was undeveloped and of no practical value. In the third edition of this book published in 1874 a considerable advance is perceived, the disease is defined more completely, but it is regarded more as a complication of insanity than an independent entity. They associate a high incidence of General Paralysis with certain occupations and modes of life stress being laid on sexual excess, dissipation and libertinism, and the occupations of soldiers, sailors, miners, prostitutes, etc. So far syphilis has not been associated with General Paralysis, though we find in 1868 Gresinger \& Westphal (13) associating General. Paralysis and Tabes Dorsalis and commenting on the prolonged period of latency of the latter. 
Sir Thomas Clouston in 1883 (14) gives a very clear, concise definition of the disease which is still of service. "A disease of the cortical part of the brain, characterised by progression, by the combined presence of mental and motor symptoms, the former always including mental enfeeblement and mental facility, and often delusions of grandeur and ideas of morbid expansion or self-satisfaction; the motor deficiencies a lways including a peculiar defective articulation of words, and always passing through the stages of fibrillar convulsion, inco-ordination, paresis and paralysis; the disease process always spreading to the whole of the nerve tissues of the body; being as yet incurable, and fatal in a few years." (Clouston; "Mental Diseases" 1880.) He expressed the opinion that General Paralysis is a disease of the outer layer of the cerebral convolutions, and as essentially a death of the mind tissue, due to the factors Which excite and at the same time exhaust the highest brain energy. He states that if women drank bad liquor and lived riotous existences they also might become General Paralytics. He . finally / 
finally concludes "I do not think there is any proof that it is syphilitic in origin."

In $1886 \mathrm{Mickle} \mathrm{(15)} \mathrm{declares} \mathrm{that} \mathrm{General}$ Paralysis is an entity rather than a complication of other forms of insanity, and gives a critical discussion of the intimate relationship between syphilis and General, Paralysis, which by that time had been freely discussed, first by Jessem \& Esmarch (16) in 1857, and later by Kjelberg (17), though Mott states that Fournier was the first to put forward the doctrine that General Paralysis is a consequence of syphilis. At this time of course it was recognised that Syphilis was a contagious disease, and its organismal nature had long been suspected. This had been speculated upon by the earliest writers on Syphilis, and Astruc (18) in 1737 speaks of the contagion as a poison or ferment and quotes an author who says it is "nothing else but a numerous brood of brisk little animaliculae, of a very prolific nature, which when once admitted increase and multiply in abundance; which lead different colonies to different parts of the body and inflame, erode, etc." 
In 1884 Lustgarten (19) described a bacillus as the cause of syphilis, but though his work was soon disproved it aroused serious attention to the subject, and paved the way for the ultimate discovery of the organism of Syphilis.

The Psychiatrists of this era recognised the great importance of Syphilis, but would not concode that it was the only factor in General Paralysis. Virchow (20) in 1858 arrived at the conclusion that Syphilis in the body attacks a "locus minoris resistentiae" and the physicians brought forward other factors such as const1tutIonal predisposition, or excess "In Baccho et Venere".

In 1898 Sir David Ferrier, quoted by Mott, stated at a B.M.A. Meeting in Edinburgh "that his experience had led him to associate Tabes and General Paralysis to such an extent that he assumed that a man suffering from either of these diseases had been infected with syphilis."

In 1900 Mott (21) following Fournier, wrote of General Paralysis as a para-syphilitic manifestation. He also wrote "I do not consider the dictum 'No Syphilis, No General Paralysis' proven, but / 
but I do think that all the evidence is in favour of the strong influence of Syphilis in the production of General Paralysis and of the closely allied pathological condition Tabes."

Kraepelin (22) in 1904 declared that "Syphilitic infection is an essential for the later appearance of paresis", but Nonne (23) refused to concede that Syphilis was more than an extremely common causative factor and that General Paralysis was not a specific Syphilitic disease of the brain.

In 1905 Schaudinn \& Hoffmann (24) demonstrated the organism known as Treponema Pallidum as the cause of Syphilis.

In 1906 wassermann (25) brought out the method of serum diagnosis of syphilis, now known by his name.

Mott (26) writing in 1910 emphasised the "para-syphilitic" nature of General Paralysis and Tabes, and prominence is given to the dictum of "Syphilization and Civilization." He accepted and endorsed the teaching of Foumier that General Paralysis with Tabes, Tabo-paralysis and primary optic atrophy form one morbid entity - viz. para-syphilis, / 


\section{9.}

para-syphilis, insidious in onset, progressive in character, and uninfluenced by anti-syphilitic remedies; that while there is one essential cause - Syphilis, acquired or congenital - there are a number of co-efficients, such as heredity or intemperance, none of which is incapable of producing the disease.

In 1909 Ranke (27) demonstrated Sp. Pallida in the Pia and vessel sheaths of congenital syphilitic brains, and finally in 1913 Noguchi \& Moore (28) succeeded in demonstrating the organism in the brains of general paralytics in twelve out of seventy cases examined. In consequence the hypothetical "para-syphilitic" condition began to be regarded as active manifestations of syphilis and they were called "parenchymatous syphilis". 


\section{EARLY DIAGNOSIS OF GENERAL PARALYSIS}

\section{OF THE INSANE.}

Experience of modern methods of treatment in this diserse seems to indicate that the prospect of recovery diminishes rapidly the longer the symptoms have been in existence. Accordingly the importance of very early diagnosis has increased. There seems to be a variance in the criteria regarded as essential for the diagnosis of General Paralysis of the Insane, and this has to some extent thrown doubt on the results reported by many writers.

Briefly we may state that we consider the following criteria to be essential for the diagnosis of General Paralysis of the Insane:-

(1) Mental Changes.

(2) Physical Signs.

(3) Characteristic Serological Findings.

\section{Mental Changes:}

Very briefly the earliest symptoms observed consist of :-

Irritability.

Moodiness . / 
Moodiness.

Forgetfulness.

Impaired Judgement.

Insomnia.

Headache.

Speech Changes.

Alteration of Character.

Change in Iibido.

Later in development are:-

Delusions.

Mania or Melancholia.

Incontinence.

Seizures.

The symptom-complex presents an infinite variation and often suggests other mental or physical diseases - Neurasthenia, Chronic Alcoholims, etc. - The fundamental symptom is enfeeblement of function, a steady process of deterioration, producing first impairment and finaliy destruction or paralysis of the mind, - known as dementia. In the earliest stages the patient is not insane - he is only a changed man. The disease us ually attacks men in mature life, heads of / 
of families, and occupying positions of responsibility - often men who have been distinguished for their intellectual gifts. Iife-long habits of courtesy, decent behaviour, and personal honour are departed from - In their place may arise a tendency to alcoholism, immorality and even criminal acts.

A group of cases has also been observed in which there are practically no mental symptoms although serological changes are characteristic "Paresis Sine Paresi". It may well be that in the future transient mental episodes and neurological phenomena, resulting from syphilis, may be noted, which may bear some relationship to, and occupy some intermediate position to General Paralysis, and be of a more benign character. "Formes Fruste" of General Paralysis of the Insane may be discovered.

It is said that $12 \%$. of patients are conscious of their defects, and they tend to present the picture of hypochondria or neurasthenia.

Practically all cases show changes in speech and writing. The sperch changes consist of hesitance, stuttering, mumbling or slurring stumbling / 
stumbling or stopping at a letter, often missing a syllable or running the whole word together, the end of the word coming with explosive suddenness after the hesitation, e.g. "Hip - pip - potamus" "Bri - sh Consh" shon."

The facies at this time often shows tremor of the lips, overaction of all the muscles, meaningless grimaces, and may reflect the man's childish pleasure in his inefficient performances, and a general state of euphoria.

It has been observed that the prognosis differs in the different types of paretic - the recovery rate being highest in the expansive forms and lower in the depressed type. This will be discussed more fully under "Prognosis", but it is now considered that the duration of the disease is more important than the severity of the symptoms .

\section{Physical Signs:}

The most frequently observed physical signs consist of pupillary changes, alteration of the deep reflexes, tremors, paralysis or hemiplegia, and loss of weight.

The pupillary changes, including ArgyllRobertson / 
Robertson pupils, associated with paresis are not necessarily sufficient to identify the clinical combination known as tabo-paresis, and form, therefore, an integral part of the picture of General Paralysis of the Insane.

$$
\text { Joffroy (29) (quoted by Southard and Solomon) }
$$

found pupillary changes in a series of 300 cases of paresis.

Altered light reflexes. Pupillary Inequality. Absent light reflex.

Irregular pupils. $78 \%$ $68 \%$ Diminished Accommodation Reflex. $17 \%$ Midriasis.

A few cases of optic atrophy have been recorded though this lesion is fortunately rarer than in Tabes Dorsalis. Optic atrophy is rarely found except in cases with well marked tabetic symptoms and signs.

The deep reflexes are usually altered, knee and ankle jerks are generally exaggerated. In Tabo-paresis they are absent, but all the intermediate variations may be found - sluggishness, inequality of knee or ankle jerks, or even only one isolated lost reflex.

Robertson (30) states that $28 \%$ of cases have sluggish or absent knee and ankle jerks. 
Byrom Bramwell (3I) states that $11.4 \%$ of tabetics pass into General Paralysis of the Insane and it is considered that one third of cases of General Paralysis of the Insane present signs of tabes.

\section{TABO PARESIS}

Tabes with Mental Symptoms.

A careful distinction must be made from cases of tabes presenting mental symptoms. These differ fundamentally in that there is no gross deterioration of the mental faculties. A striking example is a case of Tabes who travelled to Lourdes to seek a cure of his severe lightning pains. The moral aspect of his iliness had a Iways been predominant in this patients' mind, and when he failed to find relief by religious means he became depressed and melancholic and finally committed suicide. To the end he was correctly oriented, had insight into his condition, and preserved many of the amenities of his usual Iife. 


\section{JUVENI IE GENERAL PARALYSIS OF \\ THE INSANE.}

The first description of Juvenile General Paralysis of the Insane appeared in 1877 when Clouston (32) described 22 cases of General Paralysis of the Insane in congenital syphilitics. He particularly emphasises the equal affection of the Sexes in contrast with the disproportion seen in adult cases. The recognition of the juvenile form also served to discount the influence of the other factors then commonly ranked as among the cruses of General Paralysis of the Insane, e.g., sexual excess, alcoholism, lead poisoning, etc. There have been many monographs since then dealing with large series of cases - Alzheimer (33) in 1895 reported 37 cases, and Thiry (34) in 1898 described a series of 69 cases which included Alzheimers' patients. Mott (35) investigated 22 cases, and up to the end of 1903 1t was belleved that 141 cases had been recorded. SchmidtKraepelin (36) 1920, describes 54 cases and reviews the literature up to 1918. Ferguson \& Critchley (37) 1930, describe 16 cases of General / 
General Paralysis of the Insane and 12 cases of Tabo-paresis, in a series of 50 cases of congenital neuro-syphilis. Klauder \& Solomon (38) report 23 cases (quoted by Stokes). Juvenile G.P.I. in 3 rd generation of a syphilitic family has been reported by F. H. Leavit (39).

Juvenile General Paralysis of the Insane is not a very common disease, but it may be that with the wider recognition of the high incidence of infection of the central nervous system in congenital syphilitics, and familiarity with the different clinical picture presented in the juvenile form, an increasing number of cases will be diagnosed that are at present classed as "mental deficiency".

The juvenile form of General Paralysis of the Insane presents striking differences from the adult form. It has already been remarked that the sexes are affected almost equally. The average age of onset is given as 14 (Thiry), 17 (Mott), and 13, (Ferguson \& Critchley). In rare cases the onset may be very early - e.g., 6 years, or as late as 25 or 30 years. There are usually present the visceral stigmata of congenital syphilis./ 
syphilis.

It has generally been noted that the patient has presented some mental or physical abnormality, and is usually mentally backward with some degree of infantilism. The initial symptoms are usually gradual - increasing dullness, delinquent conduct, faling memory, periods of depression or excitement, and very rarely delusions of a grandiose nature. Attention may first be drawn to the child by failing vision, fits, enuresis or defects in speech or walking. In the fully developed case psychic symptoms are prominent, ranging from mere childishness to complete dementia, with disorientation, confusion, and loss of sphincter control. The child may show apathy, depression or anxiety or exaltation. Delusions of grandeur are relatively much rarer than in the adult. Disorders of conduct tend to assume the form of the semi-purposeful acts of a restless dement, rather than the deliberate anti-social acts of an adult case. Speech defects are frequent - the speech is childish, articulation is impaired, and there is stammering or explosive speech, with repetition, and in advanced cases speech is curtalled / 
curtalled, even to the point of total mutism. Tremors of the hands, face, tongue and at times of the limbs, are present. Pupilliary abnormalities are usually present. It has been noted that there is a tendency for dilatation of the pupils. Stocker (40) found midriasis in $72 \%$ of his cases, and compares this with $21.6 \%$ of dilated pupils given by Weiler (41) in adult General Paralysis of the Insane.

Optic Atrophy is a frequent feature of the congenital form of the disease. Schmidt-Kraepelin and Ferguson and Critchley report this lesion in one third of their ceses, Stocker in $17.5 \%$, and Alzheimer in 12\%. Igersheimer, $J$ (42) states that opts. Atrophy occurs in about $50 \%$ reported cases of congenital tabo-paresis. optic Atrophy is relatively rare in the adult form of the disease. $(4-5 \%$. $)$

There is often wealmess of the limbs, tremors, restlessness, choreiform movements, difficulty in walking, and the deep reflexes are exaggerated. 


\section{J UVENI IE TABO-PARESIS.}

A certain number of cases present some of the above symptoms along with definite evidence of involvement of the posterior columns of the cord. They may show marked psychological changes, speech defects and tremors, associated with absent reflexes, and sensory loss. In different cases the clinical manifestations approximate more to tabes or to paresis, but have definite evidence of both diseases. The cerebrospinal fluid tends to show changes more characteristic of paresis than of tabes.

\section{THE SEROLOGICAL CHANGES IN GENERAL PARALYSIS}

\section{OF THE INSANE}

\section{Blood.}

The Wassermann reaction in true General Paralysis of the Insane is a lmost invariable strongly positive. (Brain \& Strauss)

Stokes (44) quotes percentages given by various workers - showing negative blood Wassermann reaction in paresis varying from 5 to $18 \%$. Marie \& Ievaditi (45) compiled a table of the incidence of / 
of positive blood Wassemann reactions in a series of 295 asylum admissions in which general paralysis showed $93.4 \%$ strongly positives. Kafka (46) has recently reported $18.7 \%$ negative blood Wassemann reactions in paresis observed over a period of years. A few instances of negative Wassermann reactions on both blood and cerebro-spinal fluid in cases with symptomatic progress to a paretic outcome have been reported (Stokes) (47). Cerebro-Spinal Fluid.

Lumbar puncture was first used by Corning (48) In 1885, but was not applied to the investigation of syphilis until after 1900 when Widal, Sicard and Ravaut (49) investigated the cytology of the cerebro-spinal fluid.

The discovery of the Wassermann reaction in 1908 and its application to the cerebro-spinal fluid afforded new and more specific tests, and these added to the examination of the cells and protein gave the "four reactions" of Nonne. Five years later the gold-sol test of Lange was given an equally important place in the diagnosis of neurosyphilis. Numerous other tests and reactions have been studied, for example, Mastic, Benzoin, / 
Benzoin, Gamboge, and Collargol reactions, but the "Colloidal Gold reaction of Lange" remains the most valuable as it is by far the most delicate.

The only reaction that can be considered in any way specific is the Wassermann reaction, as a definitely positive Wassermann reaction in the cerebro-spinal fluid must be interpreted as indieating syphilis of the central nervous system.

The flocculation tests - $\theta .8$. the Sachs Gorgi test, are not reliable when applied to the cerebrompinal fluid. It may be possible to evolve a technique giving accurate results as Mackie (50) has shown that while the Wassermann reacting substance separates along with euglobulin the substance giving rise to the Sachs Gorgt reaction is related to pseudo-Globulin. Pressure of the Cerebro-spinal fluid is usually raised to about $200 \mathrm{~m} \cdot \mathrm{m}$. of cerebro-spinal fluid. Cells. The cell count is almost invariably greatly increased, and counts from 50 to 500 per c.m.m. are encountered. The cells present are predominantly / 
predominantly lymphocytes, with larger mononuclear cells forming $5-20 \%$ of the total number. Plasma cells may be found, but cannot be considered diagnostic. In a series of 25 cases of General Paralysis of the Insane Henderson \& Muirhead (5I) found plasma cells in percentage varying from 1.5 to 16 . Spirochaetes have been found after prolonged search in a few cases.

Protein. The protein is almost always increased between 40 and $100 \mathrm{mgm}$. per $100 \mathrm{c.c}$. According to Eskuchen (52) the proportion of albumen to globulin is as 7 to 3 . Euglobulin is present and may occur alone or may be associated with fibrinogen. The Wassermann reacting substances have been shown to separate on dialysis with the euglobulin. On the other hand Mackie (53) has shown that the substances which give rise to the Sachs Georgi reaction for Syphlis is related to pseudo-globulin. The globulin reactions are always positive.

Wassermann Reaction. In true General Paralysis of the Insane the cerebro-spinal fluid is always positive, and frequently very strong reactions are / 
are obtained.

These very strong reactions and their persistence under treatment have very frequently been noted to precede the clinical signs of peresis.

Dujardin's Index is high $1 / 1,1 / 2$, or at least $1 / 5$.

Wahlstrom and Widerhoe (54) compared the ventricular and lumbar fluid in 9 cases of General Paralysis of the Insane and Cerebral Syphilis, and found the Wassermann reaction positive in the lumbar fluid of all, but negative in the ventricular fluid of all but one.

Lange Colloidal Gold Reaction. This reaction is constantly of the paretic type, that is, there is complete or almost complete precipitation in the first four tubes. In the more albuminous flutds the first tube of the test (dilution $1 / 10$.) may not show such complete precipitation as the second, third and fourth tubes, but usually presents a partial decolorisation.

Typical paretic Lange test is reported as:$5555 \quad 43200$ 355532100 Changes / 
Changes in Cerebro-Spinal Fluid (Eskuchen)

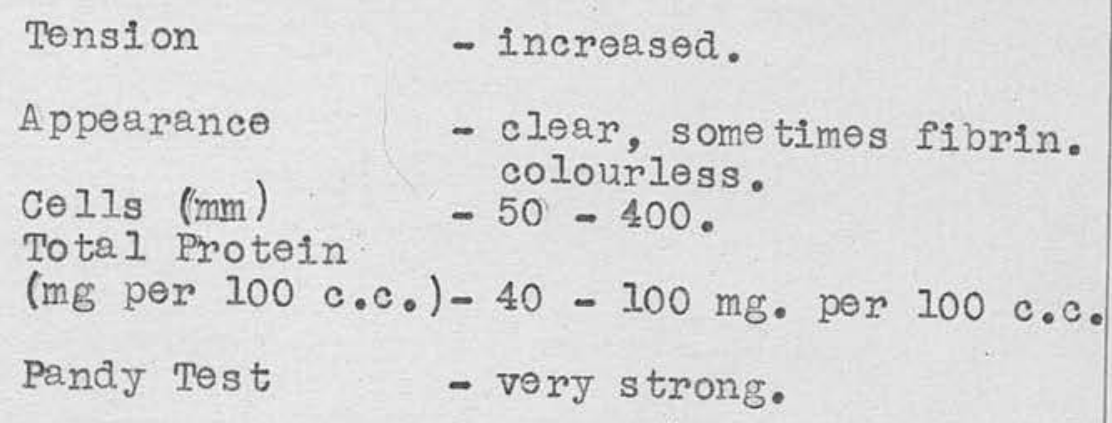

Nonne-Apelt Reaction.

$$
\begin{aligned}
& 50 \% \text { - strong. } \\
& 33 \% \text { - haze. } \\
& 28 \% \text { - nil. }
\end{aligned}
$$

Relation of

Albumen/Glob. - $7-3$.

Glucose

$-25-62$ (mg. per 100

Haemolysin

- present, slight.

Complement

- usually absent.

Ianger's Gold Sol.- Paretic.

Wassermann serum

(1/5 vol) - Positive $100 \%$.

Wassermann C.S.F.

$$
\begin{aligned}
& \text { (I/4 vol) - Positive } 80 \% \text { ) } \\
& \text { (1 - } 2 \text { vol) - Positive 20\%) } 100 \% \text {. }
\end{aligned}
$$

A single examination of the cerebro-Spinal

Fluid even if it shows all the "typical" characteristics / 
characteristics of General Paralysis of the Insane cannot be considered diagnostic, but must be assessed in conjunction with the clinical examination. This will be discussed more fully under "Paresis sine Paresi".

It has also been noted that in true G.P.I. the cerebro-spinal fluid does not improve with ordinary anti-syphilitic treatment, but the Wassermann reaction remains positive and Lange's Gold Sol test remains paretic. Dujardin's index remains high or even increases in contra-distinction to cerebro-spinal syphilis. We will discuss later under treatment the response seen in the cerebro-spinal fluid to the more recent methods of treatment, especially pyrexial treatment and prolonged administration of Tryparsamide. C.S.F. IN TABO-PARESIS.

The serological findings in tabo-paresis are usually midway between those of tabes and of paresis, the blood and cerebro-spinal fluid showing a strongly positive Wassermann reaction but the pleocytosis in the cerebro-spinal fluid may be less marked and the Gold sol test less affected in the first zone. 


\section{PARESIS SINE PARESI}

It is well known that isolated pupillary signs may preceed by years the appearance of G.P.I., so the spinal fluid may during a long asymptomatic period present the strongly positive Wassermann res.ction, positive Globulin, Pleocytosis and "paretic" Gold Sol Reaction of General Paralysis, along with a strongly positive blood Wassermann reaction. This serological forerunner of clinical general paresis has been designated by Soloman "Paresis Sine Paresi". Whilo it does not appear to have infallible prognostic value there is reason to believe that the reperted finding of "paresis sine paresi" is of grave prognostic significance. Probably it is wiser to restrict this term to cases in which the serological findings have withstood rigorous and prolonged antisyphilitic treatment. 


\section{INFLUENCE OF PYREXIA}

\section{ON MADNESS.}

It has been noted that the course of madness may be intermitted by periods of sanity, and Hi ppocrates, Galen and Sydenham each noted that the insane may improve following an acute febrile condition. Hippocrates also recorded that sufferers from quartan fever did not take the "Great Disease" (epilepsy), and if they did suffer from fits and got quartan fever the epllepsy stopped.

The frequency of spontaneous remissions and apparent recovery in the course of the disease had long been noted, and gave hope of a possibility of arresting the usual course of General Paralysis of the Insane.

In 1816 Dubuisson (55) described a remission lasting over three years in a general paralytic in whom suppuration had been induced.

In 1854 Jacobi (56) treated General Paralysis of the Insane by the production of abscesses. In 1877 Meyer (57) used Autenreith's ointment for / 
for producing suppuration of the scalp in cases of General Paralysis. In 15 cases he had 8 remissions. In 4 cases the remission lasted over three years.

Mabille (58) in 1882, and Trelat (59) in 1895 reported cases of General Paralysis of the Insane treated by the artificial production of suppuration.

Nasse (60) in 1890 noted a case of General Paralysis of the Insane improved after an intercurrent attack of malaria.

Wagner-Jauregg (61) in 1887 first suggested that malaria should be inoculated in General Paralysis of the Insane but did not carry his suggestion into practice. He meantime experimented with other methods of producing pyrexia. For example he found that by using Koch's old Tuberculin he secured a greater number of remissions and Iife was prolonged. This work was published by Pilcz (62) in 1905.

In 1909 Wagner-Jauregg (63) used a combined treatment with Tuberculin and Mercury, and has some very favourable results. In 1921 he wrote that some of the cases reported in 1909 were still living and at work. One man who was a Captain at the / 
the time had gone through the War and had been promoted to Colonel.

Later he used other bacterial products typhoid, staphylococcal and streptococcrl vaccines. His results were not so satsifactory with these methods and did not approach the standard of recovery observed when a febrlle 1 liness had supervened in addition to his treatment. Accordingly he selected Malaria as the most convenient means of introducing a controllable febrilo disease, and in 1917 (64) he inoculated nine cases of General Paralysis of the Insane with blood from a case of benign tertian malaria. Six of his original cases showed a favourable result, and in 1921 he reported that three of them were at work and showed no signs of the disease.

In 1919 (65) he inoculated a further series of cases, and since then the method has been practised almost as a routine procedure in Vienna.

Gerstmann (66) in 1921 reports results of 25 cases, and in 1922, 116 cases; and it was rapidly adopted in other countries. In 1922 the first cases in Britain were inoculated by R. Clark (67) at Whittingham Mental Hospltal. The method was rapidiy / 
rapidiy adopted in the Asylums and Hospitals in this country, and in 1929 the Report of the Board of Control (68) (England \& Wales) contains detalls of 1597 cases treated by malaria between July 1922 and July 1927.

A survey of some of the reported results of malaria treatment will be presented later.

The methods of Pyrexial Treatment that have been advocated may be classified as follows:-

1. Inoculation of Febrile Diseases:-

(a) Malaria.

(b) Rat Bite Fever. (Sodoku).

(c) Relapsing Fever.

2. Injection of Organismal products:-
(a) Typhoid vaccine.
(b) Streptococcal and other vaccines - (Staphylo. B.coll. \&cc, Ducrey's B.)
(c) Tuberculin.

3. Injection of Proteins:-
(a) Milk.
(b) Colloidal Sulphur (Sulfosin.)
(c) Peptone.

4. Physical methods :-

(a) Hot baths. (Hypertherm, Ultratherm,
(b) .)

In addition some workers combine specific with pyrexial treatment - e.g. they terminate the pyrexia by the administration of neo-arsphenamine or alternate injections of neo-arsphenamine with vacoine. / 
vaccine.

\section{THE INOCUIATION OF FEBRILE DISEASES.}

(a) Malaria.

Malaria has been used for this purpose more than any other method and already a very large experience has been recorded by many workers. Benign tertian or quartan malaria may be used, but great care must be exercised to avold malignant tertian. As a rule a strain of plasmodium is used that has been passed from one paretic to another. The plasmodium does not appear to loose virulence with repeated passage through human hosts wi thout the sexual phase in the mosquito. There are available now several strains of malaria that have been passed through over 50 human hosts and remain satsifactory - (James) (69)

B.T. or Quartan Ma laria.

Benign Tertian malaria is more generally employed, and in the majority of cases it rums a true "tertian" course, though a quotidian pyrexia is not rare. This proves very exhausting to the patient. Van Jauregg considers that the quotidian type of pyrexia in induced tertian malaria is due to particularly favourable conditions for the growth of the malaria parasite afforded / 
afforded by cases of General Paralysis of the Insane. Others believe that the Quotidian Fever occurs when donor and recipient belong to compatible blood groups. Quartan malaria is preferred in cases where there is reason to fear exhaustion or cardiac failure - the longer interval between rigors affords the patient a greater opportunity of stimulation and recovery. If it can be avoided it is preferable not to use strains of malaria derived from patients $j$ ust returned from abroad, as the virulence of the strain cannot be anticipated. Case History.

This is illustrated by the case of Mr. McM. age 48 - An early case of General Paralysis of the Insane, and apparently a good risk with no cardiac complications.

He was inoculated with blood derived from a case of Benign Tertain Malaria who had recently returned from India. The inoculation period was 8 days. The pyrexia followed a true Tertian course - in the first four attacks the maximum temperature approximated to $105^{\circ} \mathrm{F}$; in the fifth pyrexial attack the temperature rose to $105^{\circ} \mathrm{F}$. rapidly and continued to rise. Tepid sponging was employed frequently but the temperature continued / 
continued to rise and ultimately reached 107 degrees F. The patient became comatose, finally deeply unconsclous and he died after 48 hours. The Halaria was stopped at once when the temperature continued to rise by the intra-muscular injection of Quinine Hydrochloride.

\section{Inoculation of case.}

(a) Direct case - case inoculation. The usual procedure is to examine blood films from a known case of B. T. Malaria, and if the parasites are reasonably numerous (at least $1-5$ per 100 fields) then this is a suitable case from which to inoculate. Blood is withdrawn from a vein in the arm, with a sterile syringe containing 0.5 c.c. solution of $1 \%$ Sodium Citrate -5 c.c.s. of blood is ample to inoculate one, or even two recipients. It is preferable to take blood shortiy before a rigor is expected, or when the temperature is rising. The parasites are then numerous in the peripheral blood. The blood may be inoculated at once into the recipient - either intravenously or subcutaneously. Grant (70) advised that the needle should traumatise the subcutaneous / 
subcutaneous tissues if this method of inoculation is used. This is now considered unnecessary. If inoculation is intravenous it is unusual to exceed 3 c.c.s. If the recipient can be brought to the bed-side of the donor it is unnecessary to use Sodium Citrate. The blood may be transported to a patient at a distance if it is maintained at freezing point by being stored in a tube immersed in a thermos flask containing broken $1 \mathrm{ce}$. Successful inoculations have been made with blood that has been kept in this way for 24 hours.

(b) Mosquito Inoculation.

Adult female anopheles mosquitos are allowed to feed on patients who show gametocytes in the peripheral blood. The mosquitos are then removed and kept in a moist atmosphere at a temperature of $75^{\circ}$ F. Daily feeding and incubation are continued till the mosquito shows sporozoites in the salivary glands. Then some of the insects are placed on the patient who is to be infected and are allowed to bite.

Full detalis of this technique are given by James(71) - 1926 League of Nations (Malaria Commission) Report. This method requires the maintenance / 
maintenance of a sufficient stock of suitable anopheles - a matter of difficulty in this country and also the incubation period is not so certain. The malarial infection induced by mosquito bite is more difficult to cure - (James) (71).

\section{Failure of Inoculation.}

In a small proportion of cases the fever fails to develop, even though the patient has never before had malaria. Gorstmann (72) of Vienna reports $5 \%$ initial failures, Kirschberm (73) of Hamburg 10\%, and Nonne (74) 5\%. In such cases the inoculation may be repeated on many occasions, preferably with different strains of plasmodium, and successful induction of the fever often follows. Previous attacks of malaria, either induced or acquired naturally in the tropics, do not prevent successful inoculation. We have in many cases re-inoculated. the patient with Malaria within 12 months of the first attack. We successfully inoculated one patient who had suffered from malaria and blackwater fever in Africa. One of our patients - a girl aged 14 - suffering from Juvenile G. P. I. has resisted infection with malaria though she has been repeatediy inoculated with many different strains / 
strains of both tertian and quartan malaria.

Several adults also have proved resistant to inoculation.

\section{Incubation Period.}

Gerstmann (75) has stated that the quality of the inoculum, the number of plasmodia contained in it, the ease of penetration from the connective tissue into the blood stream, the accommodation of the parasites to their new environment, and the individual susceptibility of the patient are all important factors.

The influence of various types of blood in inoculation of malaria has been given much consideration in recent years. Wethmar (76) separated 65 patients who received inoculation with malaria into blood groups. He found that when the blood between donor and recipient did not match, the period of incubation was prolonged regardless of the method of inoculation. Further, the pure tertian types of fever, which are preferred because of the day of rest permitted the patient between paroxysms with this type, were seen most frequently following inoculations with unfavourable groups. Untoward / 
Untoward results in the form of temperature more than $38^{\circ} \mathrm{C}$. and chills on the first and second day after the injection were noted only in unfavourable blood groupings, and especially following intravenous inoculation. Hermann and Hlisnikowski (77) Hopf (78), Knights (79), Spierer (80), Wendlberger (81) and Muller (82) have also reported the increased period of incubation after the inoculation of patients with unmatched blood, and Wendlberger (8I) has found that the tertian type of fever more frequently follows the use of unmatched blood. Herrmann and Hlisnikowski (77) noted the common occurrence of quotidian fever after favourable blood groups had been used for inoculation purposes. Reporting the results of observations on 200 paralytic patients at the University Clinic in Vienna, Engerth and Stumpfl (83) stated that the tertian type of fever occurred more frequently in the paranoid form of paresis, wi thout regard to the type of blood used. The same authors are of the opinion that other conditions being equal a donor with a favourable blood group is to be preferred, because the chance that the first 3 to 5 febrile paroxysms will be typical / 
typical tertian is $70 \%$, or about $20 \%$ more than in those cases in which the donor's blood is incompatible with that of the patient. A tendency toward the tertian type of fever exists if an inoculation is made with blood from a quotidian type case in the second half of the developmental interval, especially 3 to 4 hours before the onset of the paroxysm, according to Hopf (78), in spite of the use of heterologous blood groups. Puntigam (84) regarded the absence of previous infection in the carrier and avoidance of quinine administration as important factors in the production of tertian fever if the strain of plasmodium is pure. In a later paper Wethmar (76) wrote that in his opinion the development of the quotidian type of fever might be due to the presence of two different generations of Plasmodiun vivax, but again traced these separately developing generations to inoculation with an homologous blood. The importance of selecting a pure strain of Plasmodium vivax containing only a single generation of plasmodia if the tertian type of fever is desired was also emphasized by Bravetta (85).

Within 24 or 30 hours of intravenous inoculation 
inoculation there may be a rise of temperature to $100^{\circ}$ or $101^{\circ}$, lasting for about 12 hours. This initial pyrexia is not seen in cases inoculated subcutaneously. It has been suggested that such initial rises of temperature are due to haemolysis in incompatible blood groups. This has not been our experience in our cases.

Wendlberger J. (86) states that :-

1. The incubation period is twice as long in incompatible as in compatible blood grouping.

2. The quotidian type of fever is more frequent in the compatible, while the pure type occurs almost always in the incom patible blood grouping.

3. The initial fever is much more frequent, of longer duration and of greater intensity in compatible groups.

Speirer (87) states that:-

It is possible to shorten the incubation period of inoculation malaria by using compatible blood groups but it is essential to inject at least 30 c.c. blood.

By subcutaneous inoculation a prolonged incubation period is secured - the average period from inoculation to the first rigor being 14 days, with extremes of five and forty-two days. By intravenous / 
intravenous inoculation the incubation period is shortened - the average being eight days, with extremes of two and fifteen days.

The incubation period does not vary with the volume of blood injected, but a heavily infected inoculum appears to shorten the incubation period. Malaria parasites may be found in the blood for a few days before the first rigor.

We have used quartan malaria in several cases the incubation period seems to correspond closely to that of Benign Tertian malaria.

\section{Choice of Patients for Malarial Therapy.}

It has been noted that certain types of cases respond much more favourably to treatment than others. In general, the earlier a case of paresis is treated the better the response. Wagner Jauregg (88) goes so far as to say that if only early cases are treated nearly 100\% of remissions cen be secured. The severity of the disease is of comparatively little moment so long as its duration is not great. Gerstmann (89) states that the prognosis is good in initial maniacal and demented forms in cases with seizures and tabo-paretics. Great care has to be exercised / 
exercised in the treatment of old, weak, or debilitated patients. If the disease is of long duration the dangers are increased and the therapeutic response is not so satisfactory. Rapidly advancing cases, so called "galloping paresis" do not respond weIl to any form of treatment, but Malaria is more likely to be successful in the short time available than any other therapeutic procedure. Very excited and maniacal cases require the strictest supervision and institutional care, because their symptoms are generally aggravated during the febrile stage of Malaria, and may continue very severe for a little time afterwards. our impression is that such cases have ultimately a better outlook than cases of mental deterioration or cases of melancholia.

Most writers report adversely on the treatment of Juvenile General Paralysis of the Insane, but Hermann (90) observed marked improvement in these cases. We have personally observed some successfully treated cases of Juvenile G. P. I.

Sex does not appear to affect the therapeutic result. Pregmancy is not necessarily a contraindication, for Unger ( 91 ) has treated a case wi thout / 
wi thout injury to the foetus. We have also observed a patient at the 7 th month of pregnancy who suffered from severe malaria and subsequently had a normal child delivered at full term. optic atrophy does not contra-indicate malaria - a proportion of cases show arrest of the atrophy on cessation of the fever, and it is practically never accelerated by the fever. FischerAscher (92) has recorded the same observation, and Hessberg (93) reports favourably on a series of cases suffering from optic atrophy. Ruge (94) divides contra-indications into two groups absolute and relative. He considers active T.B., febrile diseases of all kinds, cachexia and coronary sclerosis as belonging to the absolute group.

The principal contra-indications are:Severe cerdiovascular diserse. Pulmonary Tuberculosis. Severe Diabetes. Severe Anaemia. Severe Chronic Bronchitis. Cachexia. obesity. Nephritis. Quinine idiosyncrasy.

Age is not a definite indication for or against / 
against malaria therapy. Successful cases have been reported as late as 70 years of age, but the risks increase considerably when the age of 45 is passed. Juvenile paralyties stand the treatment very well but in general do not show such a good therapeutic response.

\section{Cardiovascular Disease.}

Cardiovascular disease has to be very carefully considered when assessing the risks of malaria therapy. Severe cardiovascular disease, whether of syphilitic orlgin or not, is generally a contraindication to malaria therapy. If it is decided in such cases to take the risk of inoculating malaria, the case must be watched very carefully indeed, and generally the severity of the fever is modified by the administration of a small dose of Quinine, 2 to 4 grains, early in the course of the disease. The patient should not be subjected to a prolonged course of treatment as collapse may supervene rapidly. Generalised arteriosclerosis, coronary disease, and myocardial failure, indicate need of great caution. Aortic incompetence or aortitis, with or without aneurysm / 
aneurysm, does not contraindicate malaria provided compensation is good. Lepine (95) does not include aortitis among the contra-indications. Mihaljeric \& Spengler (96) recorded forty cases of syphilitic cardio-vascular disease in which malaria was induced for general paralysis. only two deaths occurred in this series and neither was due to heart failure. They believe that a course of treatment for cardiac disease is imperative before malaria if untoward symptoms are to be prevented, and they consider rest in bed one of the most important points in this prophylactic therapy. Dattner \& Kanders (97) state that compensated cardiac lesions and treated pulmonary T.B. should not be considered as affecting the outcome.

\section{Pulmonary Complications.}

Many observers have noted that latent pulmonary tuberculosis may be activated after malaria. We have observed such a case and it was rapidiy fatal. Active pulmonary tuberculosis definitely contra-indicates the use of malaria. Habermann : Serefis (98) have reported the activation / 
activation of quiescent tuberculosis after malaria. Chronic bronchitis is not an absolute contra. indication, but such cases require great caution as they tend to develop Broncho-Pneumonia towards the end of the course of the fever. Mild diabetes is easily controlled during malaria treatment. There is a tendency for the blood sugar to rise during malaria, but this is not generally severe. Obarrio \& Petre (99) report a case of paresis with diabetes, who was treated with malaria, received insulin throughout and was subsequently much improved. Severe anaemia should be treated before malaria is inoculated, and if the red blood count falls below two millions during the course of the fever, this is an Indication to stop the course.

\section{MANAGEMENT OF COMPIICATIONS.}

The incubation period requires a little care. The petient should be in the best possible conditions, if possible in hospital, and certainly under daily observation. It is possible, if there is adequate supervision to have the patient at home until the first rigor occurs, but this is not genera1Iy / 
generally advisible. If there is cardiac insufficiency the patient should be at rest and given a light nourishing diet and Cardiac Stimulants. The blood is examined daily for the presence of malaria parasites. They may be present for a few days before the first rigor. Frequently a small rise of temperature of $100^{\circ}$ is noted without a rigor, and the following day, or 48 hours afterwards a true malaria rigor occurs. The patient must be nursed with the utmost care. He imposes a very severe strain on the nursing staff, and his safety, to a great extent depends on the nursing supervision he receives. When the temperature is rising the temperature should. be recorded every half hour. The temperature rises rapidly and often reaches $105^{\circ} \mathrm{F}$. in the course of two hours. If the temperature exceeds $105^{\circ}$ the utmost care is necessary and on no account should the temperature be allowed to exceed $106^{\circ} \mathrm{F}$. Rudolf gives the limit of safety as Temperature $106^{\circ} \mathrm{F}$, Pulse 160, Respiration 60 If the temperature rises to $106^{\circ} \mathrm{F}$. the patient should be sponged with tepid water until the rectal temperature falls to $102^{\circ} \mathrm{F}$. His temperature / 
temperature should thereafter be watched very carefully because it frequently rises again very rapidy. It is almost invariably possible to control hyperpyrexia by tepid sponging. If the patient shows signs of cardiovascular failure appropriate stimulants must be given. The blood pressure should be watched both during the attack and between rigors. If the systolic pressure falls below 90 millimeters $\mathrm{Hg}$. the danger point has been reached and the attack should be interrupted or terminated. The blood should be examined regularly and the red blood count made at frequent intervals. If the count falls to two milion or less the attack should be terminated. If the blood urea rises above 75 mililigrammes per cent. the patient is in danger. The urine generally shows slight albuminuria towards the end of the course and also slight traces of bile. Mild jaundice is not of serious importance but severe jaundice indicates severe liver damage. Splenic enlargement is not generally extreme and is not of importance except that care has to be exercised with very restless patients. There have been a few cases of rupture of the spleen. Nervous 
Nervous Complications.

Acute mania has already been referred to and generally disappears shortly after the cessation of malaria. Seizures are fairly frequent especially in asylum cases. They may leave residual paralysis or may clear up entirely without permanent 111 effects.

Number of Rigors.

The course of the disease is more rapid but puts the patient to a much greater strain if there is quotidian fever. A robust patient will tolerate a large number of rigors even if the fever is quotidian, but a debilitated individual should not be subjected to this severe strain for long. The fever may be interrupted by the administration of Quinine and then allowed to recur in a modified form;or, after a few rigors the infection may be terminated completely, and the patient subsequently re-inoculated with a different strain, or from a patient of an incompatible blood group.

The infection may die out spontaneously after five to ten rigors, or it may "smoulder" - 1.e. the / 
the patient does not have pyrexia or malarial parasites in the blood but after an interval of 10 - 15 weeks the malaria again becomes active and rigors with acute rises of temperature occur.

The European practice is to allow eight or ten febrilo attacks and then terminate the fever. American physicians have tended to allow a much longer course up to sixteen or twenty febrile attacks. The former method is preferable as it imposes less strain on the patient and has a lower mortality. Those cases which do not show satisfactory response can be re-inoculated after a short intervel. The termination of the fever is accomplished by the administration of Quinino; in an emergency by intra-muscular injection of Quinine, but in practically every case oral administration of Quinine is adequate. The inoculated malaria has a very benign course and is very easily cured, relapses are exceptional. We have observed in our cases the effects of Plasmoquine and Atebrin and have had very satisfactory results.

Post.f 
Post Malaria Treatment.

Immediately after the cessation of the fever the patient should receive tonic treatment, particularly the administration of Iron to counteract the severe anamia. Recovery is very rapid as a rule, and in a few weeks the patient has completely recovered from the effect of the malaria.

The Viennese practise is to follow the malaria course with Neo-arsphenamine in weekly injections of $.3, .45$, and then four injections of . 6 grammes. It has been noted that a larger proportion of general paralytics treated with anti-syphilitic drugs immediately after malaria therapy are able to return to their former occupations. Dattner (100), (quoted by Rudolf) found $25 \%$ cases of G. P. I. treated with malaria. alone returned to their previous occupations, whereas $50 \%$ treated with malaria plus Arsphenamine did so. The London County Mental Hospitals' figures give $35.6 \%$ for the first group and $41.7 \%$ for the second. Our practice has been to allow about a month for convalescence, then to reexamine the blood and spinal fluid and immediately thereafter commence treatment with Tryparsamide and Bismuth. 
Malaria appears to stimulate immune processes of the body in syphilis of the central nervous system, so attempts have been made to prevent this complaint of syphilis in persons infected with other types of Syphilis and particularly in oanly Syphilis.

Numerous observers have reported on the low incidence of neuro-syphilis in countries and peoples where both syphilis and malaria are very prevalent.

KIrschner and Van Loon (101) report a low incidence of parenchymatous neuro-syphilis in the tropics though syphilis is widespread.

Bercoritz (102) reports that in China, syphilis and malaria are prevalent but General Paralysis of the Insane and Tabes are remarkable for their absence.

Heinemann (103) made a systematic examination of the cerebro-spinal fluid in natives of Java, and finds that parenchymatous neuro-syphilis practically never occurs, but that malaria is common.

Lutario (104) finds that in Italy in the regions 
regions where the death rate from malaria is highest, the death rate from G. P. I. is lowest.

on the contrary, numerous cases have been reported in the literature in which malaria occurred in syphilitic individuals and with the subsequent development of neuro-syphilis. 22 such cases are reported by Madl \& Puntigan (105). Kyrle (106) was one of the first to employ malaria in the treatment of all forms of syphilis. He combined this method with chemo-therapy in 500 cases and reported that malaria-salvarsan therapy was superior. He noted marked improvement in the cerebro-spinal fluid in cases which prevlously showed pathological changes.

Bering (107) is also very optimistic regarding combined malaria and chemo-therapy.

Finger (108) states that this combination is superior to all others, and is indicated in cases in which pathological changes in the cerebrospinal fluid persist for $1 \frac{1}{2}$ years after the infection in spite of previous intensive treatment. The indication for malaria treatment accoralng to Memmesheimer (109) is the failure of chemo-therapeutic measures to hinder the development / 
development of changes in cerebro-spinal fluid or symptoms of central nervous system disease.

Wagner-Jauregg (110) believes that all patients with a positive cerebro-spinal fluid in the latent stage are potential paralytics and that malaria is the best method to bring about improvement.

Schamberg (111) believes that all cases with a persistent positive Wassermann reaction and other pathological changes in the cerebro-spinal fluid after an adequate course of anti-syphilitic treatment should be treated with induced malaria.

Stumpke (112) believes that malaria should only be used after the dependable snti-syphilitic drugs have failod.

Mucho \& Mras (113) states that while malaria has a beneficial effect on pathological cerebrospinal fluid it does not prevent future changes in a normal cerebro-spinal fluid even when combined with chemo-therapy. 


\section{HISTOLOGICAI CHANGES.}

We may divide changes in the central nervous system into two phases:-

(a) Those occurring during and immediately after malaria treatment.

(b) Those which appear some time after the malaria attack in cases showing remission.

There have been many exhaustive but conflicting reports on the changes observed.

Strausglen \& Koskinas (1.14) gave one of the earliest descriptions of these changes.

During the period of active malaria large numbers of plasma cells, apparently the result of massive emigration from the adventitial spaces of the blood vessels, appear singly and in groups in the brain substance. These cells frequently surround the ganglion cells in a manner resembling the glial stellati cells, a marked collection of inflammatory elements, including many macrophages, and marked proliferation of endothelial elements and an increase in capillaries are noted / 
noted in the meninges.

Iater the same authors report (115) the following characters of arrested cases soon after malarial treatment.

Inflammatory elements are more persistent In the meninges, the subcortical portion of the brain, the brain stem, and medulla oblongata than in the cortex. Iymphocytes predominate over the plasma cells. As the duration of the remission increases the inflammatory changes decrease and the parenchymatous changes are brought to a standstill.

Bruetsch and Bahr (116) stressed especially the proliferative changes in the capillary endothelium during the paroxysms and suggest that these should be regarded as part of the reaction of the reticulo-endothelial system.

Bruetsch (117) states that the histiocytes are transformed into active highly phagocytic cells by the malaria plasmodium. There is a marked numerical increase of this cell type observed in the liver, spleen, bone marrow and lepto meninges of the central nervous system. The endothelial cells of the capillaries of the brain 
brain cortex are stimulated during acute malaria, and the changes invoked are responsible for the varied degrees of permeability observed during and after malaria treatment. 


\section{PHYSICAI METHODS OF PRODUCTION}

\section{OF PYREXIA.}

As I have not personally observed cases treated by this method I will only present a short review of the methods adopted at present and their efficacy.

The elevation of the Patient's temperature by hot baths, steam baths, infra. red baths, etc., have been almost entirely abandoned. They are not very effective and are frequently dangerous. $\mathrm{Ba}$ Ineo-thermo-therapy is ineffective and frequently causes deaths - (Mehrtens \& Pouppirt) (118).

High Frequency electric currents were first used by Neymann and osborne (119) in 1929.

The diathermy current has been combined with the use of hot air cabinets or radiant heat cabinets. All such methods are capable of producing pyrexia of any desired degree, but they vary in their safety and efficiency. The electric blanket produces a very slow rise of temperature and is not therapeutically effective. The / 
The air-conditioned cabinet was introduced by Simpson, Kislig \& Sittler (120). In these cabinets the air temperature, relative humidity and air velocity are controlled. A high external temperature tends to cause a higher pulse rate and greater distrabance of circulation. Air conditioning accelerates the rise of temperature and makes a high temperature plateau easily accessible.

The most recent method and one that is now within the compass of most General Hospitals, is by induced currents.

A vacuum tube oscillator which generates a high frequency current of 12 megacycles per. second, transmits the current through a coil. An alternating electro-magnetic field of the same frequency is set up. If then any conductor is placed in this magnetic fleld, voltage will be induced in that conductor, as a result of which induced currents will flow - (these are known as eddy currents) - and will produce heat in the conductor. This is known as heating by electro-magnetic induction. 
If the human body is introduced into this field it will of course be heated and the greatest heat will be produced in the tissues of greatest conductivity. The most conductive tissues are the most vascular and the blood itself, skin, fat and bone are poor conductors, and so they are not nearly so much heated when subjected to the same intensity of current.

This principle has been combined with an air-conditioned cabinet to form the "InductoTherm" . This cabinet encloses the whole patient except the head and neck. A rubber collar encircles the neck. The rectal temperature is recorded continuously by a thermo couple enclosed in a sealed tube and this is registered on the exterior of the Cabinet. Neymann \& Holmquest (121) have described the details of $\mathrm{such}$ an apparatus.

The fever is produced rapidly by electromagnetic induction - the coll is placed under the patient about $2 \frac{1}{2}$ inches from his body. The amount of current passing through the coil is regulated by a rheostat. Mercurial thermometers used to record the temperature must be 
be changed frequently (every 2 weeks) as they are soon affected by eddy currents. (Bessemans, Rutgers \& Van Thielen) (122).

The temperature rises rapidy and in 60 or 90 minutes the desired pyrexia is reached usually $105^{\circ} \mathrm{F}$ - The current is cut off before this figure is reached and the rectal temperature is found to continue to rise for about $30-60$ minutes. On no account should $107^{\circ} \mathrm{F}$. be excerded. The air-conditioning plant then maintains a temperature of $120^{\circ} \mathrm{F}$. and a humidity of $60-70 \%$. The pulse rate increases and there is marked perspiration with loss of water and salt - the capillary circulation is increased and there is a fall of systolic blood-pressure. Heat Stroke is very unusual and should not occur in well regulated electro-pyrexia. The temperature can be readily maintained at therapeutic levels - about $105^{\circ}$ for a period of $5-8$ hours.

The following tables (From Neymann) (123) compare the results in G. P. I. of Malaria and Electro-pyrexia. 


\section{OF DEMENTTA PARALYTICA}

\section{WITH EIECTROPYREXIA.}

\section{A UTHORS}

Neymann and Osborne.

King and Cocke.

Cortesi.

Ne ymann and Koenlg.

Perkins.

Wilgus and Lurie.

Pacheco e Silva, Passos, Fajardo \& Marques de Carvalho. Hinsie and Blalock.

Schiff, Misset and Trelles. Prior.

Halphen, Auclair, Crouzon. Bamford.

Bishop, Horton and Warren. Schamberg and Butterworth. McKay, Gray and Winans. Neymann, Feinberg, Markson \& Osborne.

Epstein and Paul.

Graham.

Worthing.

Freeman, Fong and Rosenberg. Simpson, Kislig and Sittler. Schallenberger.

Martinez.

Wilgus and Kuhns.

Hooverson and Morrow.

Neymann and 0sborne.

Jones.

Beorman, Hirschfield,

Epstein and Paul.

Cullins, Morgan \& Seymour.

Natrass and Evans.

Barnacle, Ebaugh \& Ewalt.

Kleiner.

Neymann, further cases to date.

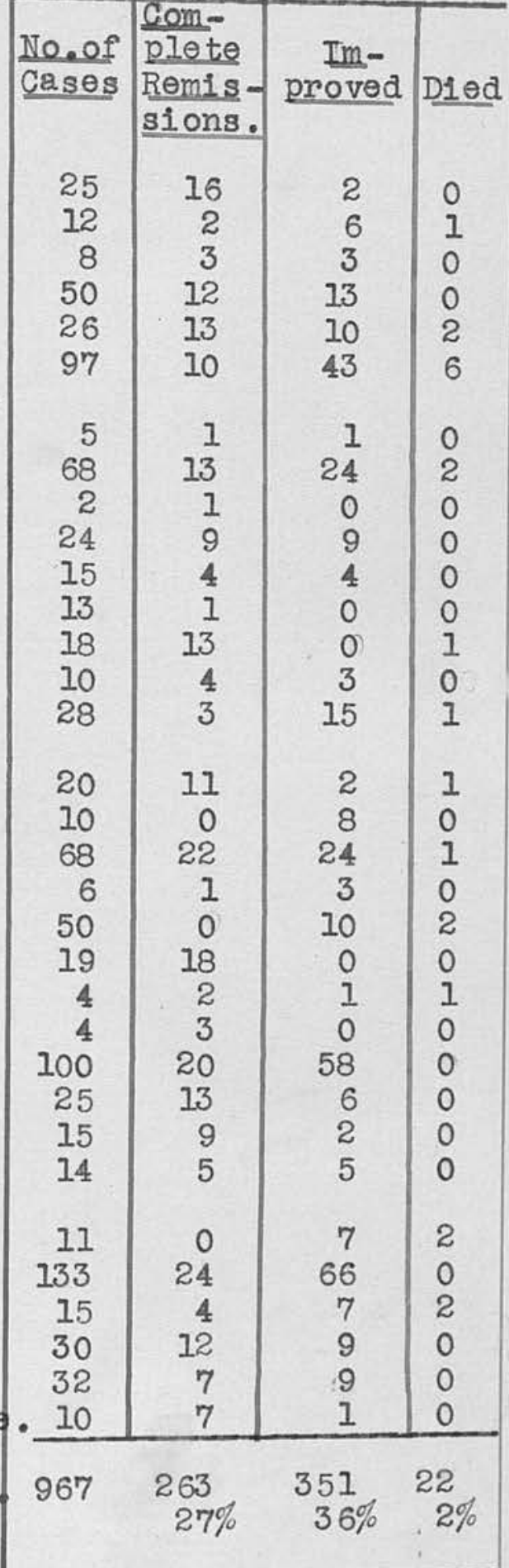




\begin{tabular}{ll} 
& OF \\
DEMENTIA & PARA LYTICA \\
\hline
\end{tabular}

WITH

SODOKU, MAIARIA AND DIA THERMY.

\begin{tabular}{|c|c|c|c|c|c|}
\hline Preatment. & $\begin{array}{l}\text { Remission } \\
\text { Returned } \\
\text { to Former } \\
\text { occupation. }\end{array}$ & Improved. & Arrested. & $\frac{\text { Non- }}{\text { Arres - }}$ & Died. \\
\hline $\begin{array}{l}\text { Sodoliu. } \\
\text { Ma.laria. } \\
\text { Dia thermy. }\end{array}$ & $\begin{array}{r}8 \% \\
22 \% \\
24 \%\end{array}$ & $\begin{array}{l}22 \% \\
22 \% \\
26 \%\end{array}$ & $\begin{array}{l}24 \% \\
26 \% \\
30 \%\end{array}$ & $\begin{array}{l}36 \% \\
12 \% \\
20 \%\end{array}$ & $\begin{array}{l}10 \% \\
18 \% \\
0\end{array}$ \\
\hline
\end{tabular}

N.B. Died - Died as Results of Treatment.

Juvenile G. P. I. may be favourably influenced

in the few cases recorded.

CIINICAL RESULTS IN THE TREATMENT OF

JUVENIIE GENERAI PARESIS

WITH EIECTROPYREXIA.

\begin{tabular}{|c|c|c|c|c|}
\hline Authors & $\frac{\text { No.of }}{\text { Cases }}$ & $\begin{array}{l}\text { Markedly } \\
\text { Improved }\end{array}$ & $\stackrel{\text { Im }}{\text { proved. }}$ & $\begin{array}{l}\text { Unim- } \\
\text { proved. }\end{array}$ \\
\hline $\begin{array}{l}\text { Palmer. } \\
\text { Simpson, kislig and } \\
\text { Sittler. } \\
\text { Potter. } \\
\text { Menninger. } \\
\text { Neymann. }\end{array}$ & $\begin{array}{l}1 \\
4 \\
2 \\
1 \\
1\end{array}$ & 1 & $\begin{array}{l}4 \\
1 \\
0 \\
0\end{array}$ & $\begin{array}{l}0 \\
0 \\
1 \\
0 \\
1\end{array}$ \\
\hline TOTA I........... & 9 & 2 & 5 & 2 \\
\hline
\end{tabular}


Chemo-therapy should be combined with electropyrexia.

The mortality with electro-pyrexia is lower than in most series of malaria treated cases, but this factor is largely dependent on close supervision of the patient during the fever, and also on selection of suitable cases and individual judgment in terminating the fever when danger appears to threaten. The death rate is 22 (2\%) in 967 cases.

Neymann (123) recommends a temperature curve with a high febrile plateau.

At least eight hours of continuous temperature above $39.7^{\circ} \mathrm{C} .\left(103.5^{\circ} \mathrm{F}.\right)$ should be employed. In adition, during at least two of these hours the temperature should range slightly above $41^{\circ} \mathrm{C}$. (105.8 F.). This is a critical temperature for Treponema pallidum and kills most of them.

If early cases are selected for treatment a high recovery rate (80\%) can be reached. 


\section{CHEMO - THERA PEUTIC TREA TMENT}

A FTER MAIARIA.

In the present series of cases the great majority have been treated by anti-syphilitic drugs - often before the pyrexia and invariably after the cessation of the pyrexia. We have not thought it advantageous to attempt to use chemo-therapy and fever simultaneously. Many of the anti-syphilitic drugs have some curative action on malaria and the patient is already prone to develop such complications as jaundice from the fever a lone.

The proceedure adopted in this series has been to re-examine the cerebro-spinal fluid soon after the malaria has been cured, and then to administer Tryparsamide and Bismuth by the interrupted method, many courses being given and the treatment is continued for a period of years until the maximum clinical recovery is achieved and until the tests of the blood and cerebro-spinal fluid have returned to normal.

The dose of Tryparsamide given is 3 grammes per / 
per week and this is given for 10 consecutive weeks, then there is an interval of 4 weeks and the "Course" is repeated. In this way about 120 - 150 grammes Tryparsamide may be given per annum.

Bismuth (either an insoluble metallic preparation or an oil-soluble preparation) is given at the same time.

The chemo-therapeutic attack seems to increase the percentage of satisfactory remission; it is necessary to control other syphilitic disease such as aortitis, and in a considerable number of patients $(32 \%)$, both blood and cerebro-spinal fluid have returmed to normal. This appears to make the prognosis much more favourable both for Iife and freedom from relapse.

The drugs are of low toxicity and complications following their use are few if reasonable precautions are taken. The utmost care is necessary to detect toxic amblyopia due to Tryparsamide - an examination of the optic discs and of the fields of vision at the beginning of treatment and at intervals throughout treatment wi11 / 
will effectually safe-guard the petient. Other toxic sequelae are not common with Trypersamide a few cases of jaundice and of dermatitis have been observed. As a rule, there is a pronounced tonic action with increase of weight. 


\section{COMMENTARY ON CASES.}

It has been ascertained that

180 cases of General Paralysis have been inoculated with malaria in The Edinburgh Royal Infirmary and on analysing the figures in TABIE I, there is no significant difference between the different types of Malaria. 
TABIE (I).

$\frac{\text { TOTAL NUMBER OF CASES }}{\text { TREA TED IN }}$

EDINBURGH ROYAL INFTRMARY $1925-38$.

TYPES.

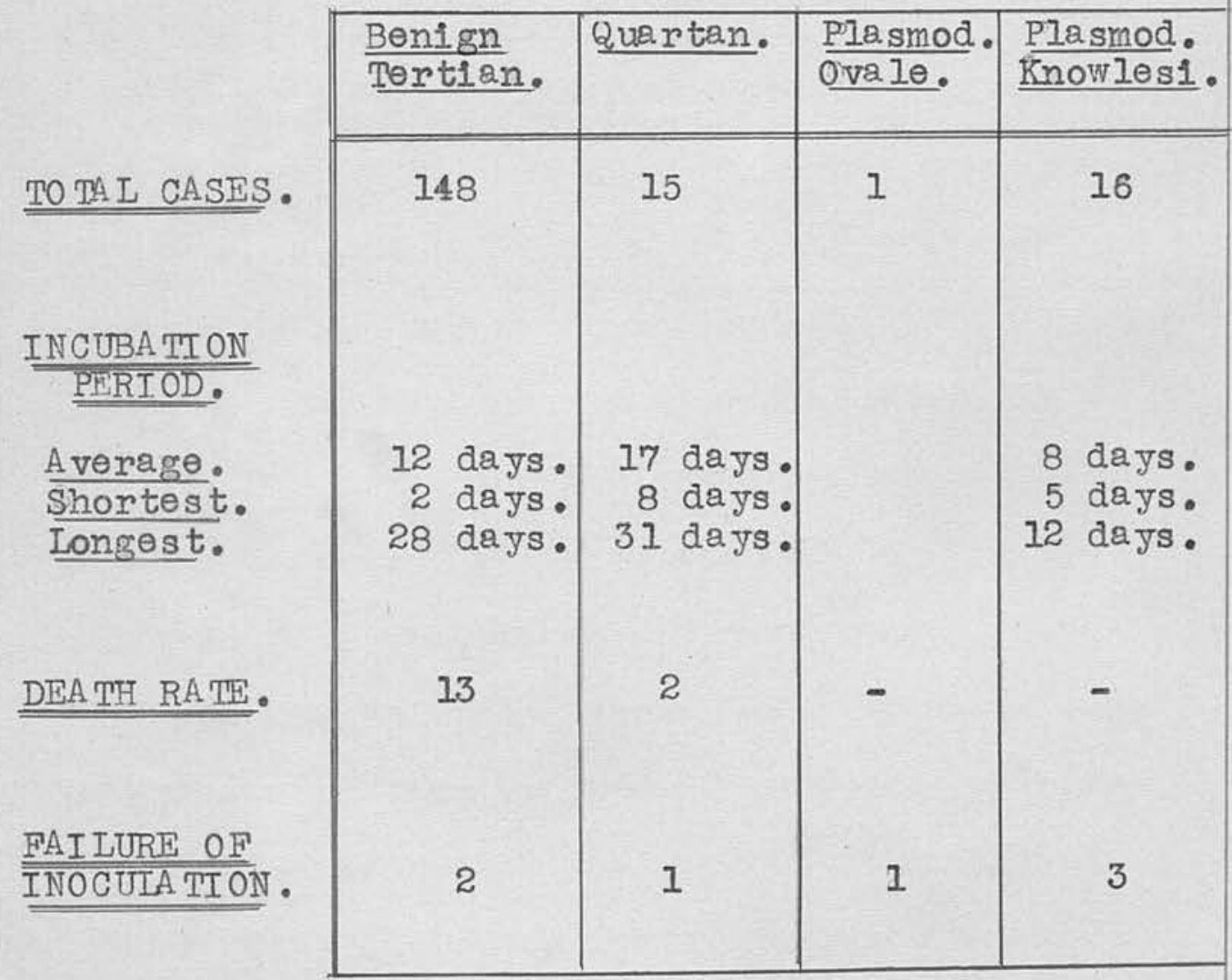

TOTAL DEATHS.

15

$\underline{\underline{9.25 \%}}$

TOTAL FAI LURES INOCULA TE. $7 \quad 4 \%$

TOTAL CASES

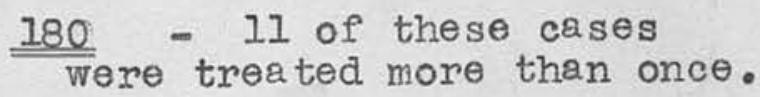

N.B. FIve cases died in Medical Wards - therefore difference in mortality, between Tables I and II. 
The great majority have been treated by Benign Tertian Malaria and this is now invariably used, as supplies of a reliable strain of Benign Tertian malarial blood can be obtained at very short notice from the Ministry of Health in Iondon.

\section{FAI LURE OF INOCUIA TION.}

Seven cases failed to develop malaria after inoculation. In some cases this was an apparently true resistence of malaria, as they resisted inoculation on several occasions.

One such patient was a case of Juvenile General Paralysis who had never suffered from malaria before. Patients who had previously suffered from malaria abroad have been success fully inoculated - one such patient was treated In spite of having suffered from severe malaria and black-water fever while resident in Africa.

In many instances faulty inoculation must be attributed to faulty technique or to the inoculum having been unduly delayed in transit. Successful inoculation has been secured from material which has been over 24 hours in transit, but / 
but such a delay is generally undesirable.

\section{MORTA II TY.}

The death rate does not appear to vary between the different strains of malaria employed and though Quartan Malaria should theoretically have superiority from this point of view, no significant difference was noted. Plasmodium knowlesi was used for the treatment of 16 patients without a fatality and with this parasite it seems possible to anticipate to scme extent the onset of serious symptoms, by following the rise in the parasite count. If the parasite count becomes extremely numerous, very severe symptoms are probable. The parasite count does not appear to be equally reliable in this respect with other strains of malaria.

of the 180 cases, 15 died during or immediateIy after the fever, giving a mortality of $9.25 \%$. This is substantially in agreement with the majority of published reports, and though it might be considered unduly high, many of the cases treated have been of the"desperate" type, known to be / 
be bad risks. The mortality can be substantially reduced, if such bad risks are excluded, but in view of the occasional success of the treatment even in advanced cases, it was considered justifiable to give the patients the opportunity of fever treatment.

It has already been pointed out when discussing the merits of fever induced by physical means, that it may be possible to treat patients with serious cardiac weakness, if the maximum temperature, the duration of temperature and the frequency of the temperature are absolutely under control. Electrically induced fever should be associated with very low mortality.

The majority of deaths are directly due to cardiac failure. This may develop very suddenly and is usually recognized towards the end of the febrile period. Progressive fall in blood pressure or an unduly rapid pulse, cyanosis and general exhaustion are warning signs. Many of the patients respond to prompt termination of the fever and stimulation. Several of the patients in this series presented unmistakable evidence of chronic syphilitic aortitis and this was not considered / 
considered an absolute contra-indication provided that the myocardial function was satisfactory. Obese patients are generally unsatisfactory subjects and are liable to sudden circulatory collapse.

One patient died in hyperpyrexia. This is explained by the use of a strain of malaria, the behaviour of which was not known, as the blood had been taken from a woman who had just returned from India. To some extent, the nursing technique may also have been faulty, in that the danger was not recognized at a sufficiently early point - the temperature had reached $107^{\circ}$ before active anti-pyretic measures were instituted.

One death may be attributed to severe diabetes, from which the patient suffered. It was recognized that this patient was a very bad risk, but other methods of treatment had proved of no avail. One patient eommitted suicide during the course of malarial treatment. Another patient was found dead and was presumed to have committed suicide shortly after leaving hospital on the completion of malarial treatment. Making the fullest allowances for such factors, it will be 
be seen that malarial treatment of General Paralysis of the Insane is a serious undertaking with a direct mortality of approximately $10 \%$. This treatment is only justified by consideration of the grave prognosis in the disease treated by other means or left untreated.

\section{GIINICAI RESULTS OF TREATMENT \\ IN \\ 80 CASES.}

In attempting to ascertain the results of treatment in the present series of 80 cases which have been observed personally over an adequate period of time, no attempt has been made to separate the results due to malaria and the results which may be attributed to anti-syphilitic drugs in particular Tryparsamide and Bismuth. Prac tically all the patients were treated by both methods. A few were treated by Tryparsamide and Bismuth before malaria was administered. In other cases the fever therapy was followed by the administration of drugs. The / 
The period of observation varies from one year up to ten years and I am greatly indebted to many of my colleagues, for their co-operation in attempting to trace these individuals and reporting their observations on the patients after the $y$ had left Edinburgh.

There is no accepted plan for assessing results of treatment in General Paralysis of the Insane, but a rough clinical guide has been adopted as below:-

\section{CURE.}

A patient is considered cured if he has been able to resume his life without supervision and carry on a similiar occupation. He may be considered cured in spite of positive serological tests.

IM PRO VED.

The patient shows very striking physical and mental improvement and does not require institutional care or strict supervision, but has not been able to resume his former occupation and mode of Iife.

STATIONARY. 
STA TIONARY.

The patient has not improved mentally or physically, but further physical and mental deterioration has not been observed.

\section{WORSE.}

Patients who have shown either further mental or physical deterioration are included in this category.

No attempt has been made in the present series to trace progressive improvement in the serological findings of the blood and cerebro-spinal fluid during the course of treatment. As a rule the blood and cerebro-spinal fluid were re-examined immediately after the termination of the malaria and thereafter at intervals not exceeding six months. In the present study, the last findings in the blood and cerebro-spinal fluid have been considered, and all the cases in this series have been under treatment for at least one jear. Without exception the patients showed serological improvement. In a few, slight improvement was noted at a very early stage and the rate of improvement varied, but did not appear to be parallel to the clinical cure. 

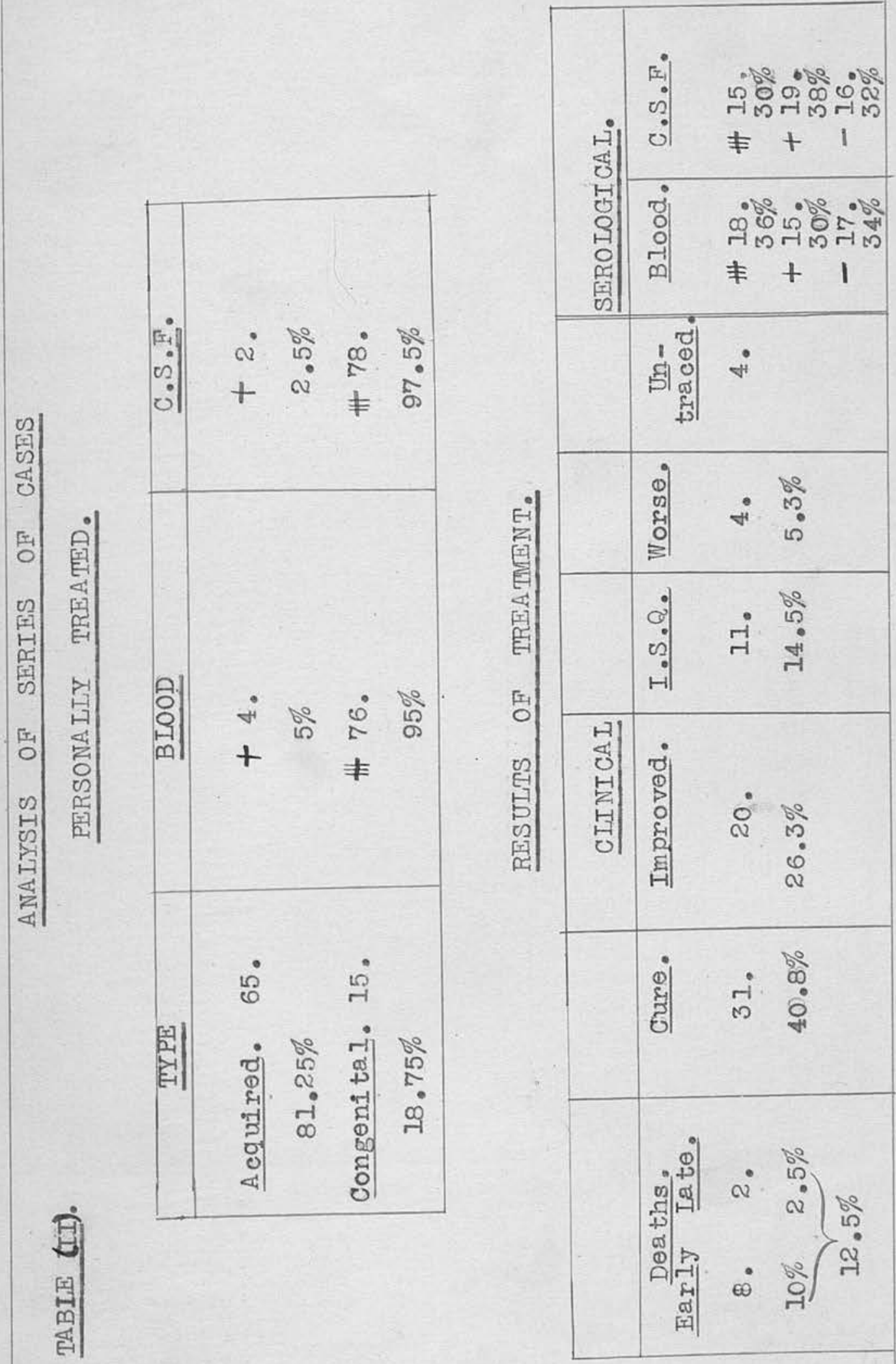
In the present series of 80 cases, 31 patients $(40.8 \%)$ are classified as cured. This proportion is slightly higher than the average published and this is probably due to the fact that many early cases are included among 'cures'. In general the pritients of the present series were treated before mental symptoms rendered them certifiable as insane.

Twenty cases (26.3\%) are classified as improved and these patients are in their own homes and attend as out-patients. Many of them are employed, but not in the same occupation or in such responsible occupation as that which they followed proviously, or physical symptoms and signs have developed which renders it impossible to classify them as cured. It has been observed that certain patients whose mental symptoms are in abeyance and are probably cured, have developed signs of Tabes Dorsalis. The signs of Tabes Dorsalis in some instances have been progressive, but none of the cases present severe symptoms. One patient, formerly treated for General Paralysis of the Insane, now shows signs of Tabes Dorsalis with Charcot's Disease affecting both knees. The / 
The rate of improvement has been extremely variable. In a few patients it has been observed that all the mental symptoms clear up at a very early stage of the malarial treatment and at the same time tremors disappear and speech becomes clearer. Such patients usually show uninterrupted progress to complete cure. A few patients become extremely confused and disoriented during the fever, but this disappears when the febrile attacks are terminated. A fow became maniacal, necessitating certification and confinement in a Mental Hospital; but practicelly all such cases subsequently showed very rapid and pronounced mental improvement. While attacks of mania renders it difficult to treat such patients at home or in General. Hospitals, they are not altogether of bad prognostic significance.

The degree of improvement does not appear to be related to the gravity of the mental symptoms before treatment, but it is directly related to the duration of the disease before treatment is necessi ta ted.

In general, it appears in the present series that the manic and grandiose types have ultimately improved / 
improved more than those in which there was gross deterioration of speech and conduct.

Eleven cases are recorded as stationary. While physical deterioration has not been conspicuous, the patients are unfit for employment and are accommodated either at home or in Menta.1 Institutions, where they are occupied with simple manual duties. Many of the cases of Juvenile General Paralysis fall into this category. The disease appears to be arrested, but Juvenile cases do not show the same restoration of mental functlons and are not readily educated to a useful standard of occupation.

Four cases were considered to have been made worse as a result of the malarial treatment. One patient developed severe albuminuria, which was ascertained to be due to nephritis of a glomerulotubular type and while his mental condition remained fairly satisfactory, he showed physical deterioration and died some months after treatment. The remaining cases showed no improvement in their mental state and they did not appear to recover on the termination of the malarial treatment. Physical and mental deterioration were progressive and / 
and death occurred comparatively rapidly. The course of their disease appeared slightly more rapid that the average untreated case of General paralysis and it is probable that the debility produced by the fever accelerated their deaths.

It is difficult to assess the serological Results in the present series of cases as the period of observation varies and on studying the Case Records it is obvious in the majority that the reversal of the serological findings only occurs after treatment wi th Tryparsamide and Bismuth over a period of two to five years.

Completely normal Serological Findings and cerebro-spinal fluid occurred in 16 cases (32\%), and in all these cases the results appear to be permanent as there has not been a return to positive after treatment was suspended.

An improvement in the Serological returns was observed in the blood in $64 \%$ and in the serological Findings in $70 \%$. In twelve cases both blood and cerebro-spinal fluid became ne gative. The serological improvement of ten lagged behind the clinical improvement and in general it may be stated that those cases which have shown good clinical / 
clinical results, show serological improvement, and the cases that are not improved clinically, show little or noi serological progress. The only exception to this appears to be in the group of Juvenile Cases, where though serological improvement may be ultimately achieved, little or no mental improvement is found.

A resistant blood Wassermann Reaction is often indicative of active syphilitic disease in other systems, particularly cardio-vascular disease. Many of the patients were found to have definite evidence of aortitis, and in such cases the Wassermann Reaction was usually positive.

\section{EFFECTS ON OTHER SYPHIIITIC MANIFESTATIONS.}

This system of treatment appears to have a uniformly beneficial result on other syphilitic manifestations. While great care is necessary in the early stages of treatment with patients suffering from aortitis and myo-cardial degeneration, when they are convalescing from the fever, improvement may commence and it is usually progressive. After severel months they are usually able to undertake greater exertion, and the 
the state of the circulation appears to be improved.

The progress of primary Optic Atrophy appears to be very little affected by malarial treatment, but prolonged treatment wi th Tryparsamide and Bismuth often delays the progress of the atrophy and in one case in the present series, the disease appears to have been arrested, leaving the patient a useful amount of vision.

\section{Syphilitic disease of the liver does not} appear to be a contra-indication of this treatment, as one patient with quite a severe degree of cirrhosis is being successfully treg ted and shows no evidence of further liver damage.

Generalized arterial degeneration renders the prognosis a little more grave, but is not incompatible with satisfactory therapeutic results. In juvenile paretics, deafness and opacities of the cornea do not appear to be improved. Tabetic manifestations were almost invariably improved and the patients suffered from fewer lightning pains. 


\section{JUVENITE GENERAL PARAIYSIS}

\section{OF THE INSANE。}

There were 15 cases in the present series.

In all, the blood and cerebro-spinal fluid gave strongly positive findings. There were no deaths under treatment. Three cases have recovered completely and in two of these the blood and cerebrospinal fluid is negative and the findings in the third case are very much improved. Three cases are recorded as improved and the remainder are stationary.

In one of these cases recorded as stationary, I have received a report from Dr. Bailey, Medical Superintendent of Gogarburn Institution:-

"he was undoubtedly suffering from Juvenile General Paralysis of the acute maniacal type. He was treated with malaria and tryparsamide. As a. result of this treatment this condition has been definitely arrested. Wassermann Reaction in his blood is negative and only faintly positive in the C.S.F. Physically there are no residual symptoms of general paralysis, except that there is a partial atrophy of both optic discs with consequent impairment of vision. Mentally, however, there is considerable intellectual impairment. His mental age is that of an average child of 8 years..."

The cases recorded as cured are all following useful / 
useful occupations, though none of them have a high degree of mental development. These results are equal to those reported in the literature. Tennent, T. (124) reported 14 cases, 5 of whom had recovered to a moderate extent. Stewart, H.H., (125) reported one case with satisfactory clinical and serological recovery. 
The History of the Treatment of General Paralysis of the Insane has been outlined - first the recognition of General Paralysis of the Insane as a clinical entity, and its relation to Syphilis, later the pyrexial treatment by malaria and other fevers, then chemo-therapy, and more recently electro-pyro-therapy.

Accurate methods of Diagnosis of General Paralysis of the Insane (including the rare Juvenile form) are discussed.

The Technique of Malaria Therapy is discussed, including the method of inoculation, the choice of the type of malaria, the selection of suitable cases, precautions during the course of the fever and the risks entailed.

A brief outline of the Treatment of General Paralysis of the Insane by anti-syphilitic drugs is given; but combined treatment with Tryparsamide and Bismuth is preferred.

Physical Methods of induction of fever are reviewed. / 
reviewed.

\section{REVIEW OF CASES PERSONALIY OBSERVED.}

180 Cases of General Paralysis of the Insane have been treated in Edinburgh from 1925 - 1938. Records of these cases have been perused.

80 Cases have been observed by the writer over an adequate period of time.

The proceedure adopted was a combination of Malaria Treatment and Tryparsamide and Bismuth Therapy.

The results of treatment of 80 Personal Cases are discussed.

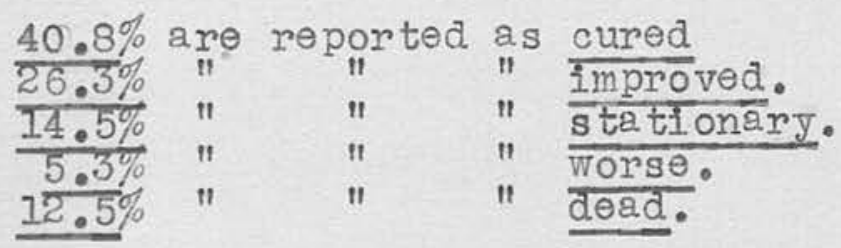

A standard is described by which the cases are judged.

The Serological and Cerebrospinal Fluid changes after treatment are reviewed and the results are correlated to the clinical findings. 


\section{REFERENCES。}

Historical.

1. Robertson, G.M. : Jour. Ment. Science, 1923. Vol. LXIX. pp. I - 24.

2. Bond, $\mathrm{H}$.

: Report of Board of Control, (England \& Wales) 1929.

3. Wiliis, T.

: "De Anima Brutorum" Iondon, 1672.

4. Haslam, J.

5. Cox, J.M.

6. Argyll-Robertson.:

7. Georget.

8. Bayle, A.J.L.

9. Bayle.

10. Calmeil.

11. Pritchard, J.C. :

12. BuckmilI, J.C. \& Tuke, D.H.

13. Gresinger \& Westphal.
: Observations on Insanity, 1798 .

: Practical Observations on Insanity. 1804.

Edinr. Med. Jour. 1869.

"De La Folie" 1820.

Recherches Sur les Maladies Mentales. 1822. Thesis for M.D. Paris.

: Maladies of the Brain and 1 ts Membranes. 1826.

: "De la Paralysie consideree avez les alienes".

"A Treatise on Insanity and other disorders affecting the Mind."

"A Manual of Psychological Medecine" 1858.

Jour. Ment. Science. XVI,

: 162. Jour. Ment. Science XVII, 506. Transl. by J. Rutherford.

14. Glouston, T./ 
14. Clouston, T. : Mental Diseases, Ist. Edit., 1880.

15. Mickle, W.T. : General Paralysis of the Insane. 2nd. Edit., 1886.

16. Jessen \& Esmarch: Allg. Z schr. f. Psychiat. 1857 .

17. Kjelberg, G. : (Abs, in Jahresb.) XIV.20.

18. Astruc. : Venereal Disease i, 45. 1737.

19. Lustgarten. : Wien. Med. Woch. XXXIV. 1389. 1884.

20. Virchow. : Arch. f. Path. Anat, XV. p. 229. 1858 .

21. Mott.

: Archives of Neurology. 1900 .

22. Kraepelin, E. : "Psychiatrie" Ieipzig. 1904. 11.

23. Nonne, M.

: Syphilis and Nervensystem. Berlin. 1902 .

24. Schaudin \& Hoffmann, E. Arbeiter a.d. Kaiserl

: Gesundheitsamte. 1905. Vol. XXI1. p. 527.

25. Wassermann.

: Deutsch. Med. Woch. 1906. Vol. xxxil. p. 450 .

26. Mott.

: Syphilis of the Nervous System. 1910.

27. Ranke.

: Z schr. f.d. Erforsch u. Behandl d jugend I Schwachsinus 1909. 11. 32. 81. 211.

28. Noguchi, H. \& Journ. Exper. Med., 1913. Moore, J.W.

29. Southard \& Soloman H.C.

: xv11. p. 232.

Nourosyphilis, Boston, : 1917.

30. Robertson / 
30. Robertson, G.M. : Edin. Med. Jour. 1913, $\mathrm{X}, 293$.

31. Bramwe11. B.

: Clinical studies. VI. 1908. p. 143 .

32. Clouston, T.S.

: Jour. Ment. Sc. $1877-8$, 23 , p. 149 .

33. Alzhoimer.

: Allg. Zeit. f. Psych. 1896. III. p. 533 .

34. Thiry, Ch.

: De la paralysie générale progressive dans le jeune age. Nancy. 7898.

35. Mott, F.W.

: Arch. Neur. 1899, I, 250.

36. Schmidt-Kraepelin.: Ueber die Juvenile paralyse Berlin. 1920.

37. Ferguson F.R. \& : Brit. Journ. Childrens' Critchley, $M$. Diseases, 1930, XXVII, I.

38. Klauder \& Solomon.: Quoted by Stokes, J.H.

39. Ioavit.

40. Stocker, $W_{\text {. }}$

41. Weller, K.

42. Igersheimer.

43. Brain $W_{0} R_{0} \&$ Strauss, E.B.

44. Stokes, J.H.

45. Marie \& Ievaditi.
: Arch. Nour. \& Psychiat. XXVI, 665 .

: Zeits. f. Neur. u. Psych. 1914, XXVI, 564 .

: Zeits. f. Neur. u. Psychiat, 1910, II, 198.

: Syphilis \& Augen, Berlin, 1918.

: Recent advances in Neurology. 1929.

: Modern Clin. Syphi lology. 1934.

Quoted Stokes. Mod. Clin. Syphi lology. 1934. 1105.

46. Kafka. / 
46. Kaflia.

47. Stokes, J.H.

48. Coming.

49. WidaI, Sicard \& Ravaut.

50. Mackie, T.J.

51. Henderson \& Muirhead.

52. Eskuchen.

53. Mackie, T.J.

54. Dahls trom \& Widerhoo.

55. Dubisson.

56. Jacobi.

57. Meyer.

58. Mabille.

59. Trelat.

60. Nasse.

61. Wagner-Jauregg.

62. PIICZ.
: Quoted Stokes. Mod. Glin. Syph1 lolo g7. 1934. 1105.

: Modern Clin. Syphilology 1934. 1122.

: New York Med. Journ. 1885, XIII, 483.

: Rev. Neurolog. 1903. $\mathrm{XI}, 437$.

: Journ. Path \& Bacter $1923, X X V I, 120$.

: Rev. Neur. \& Psych. $1913, X I, 195$.

: Die Lumbal punktion, Berlin, 1919.

: Journ. Path \& Bacter 1923, XXVI, 120 .

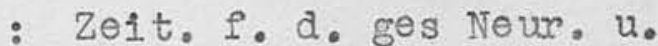
Psych. 1921.

: Des vesanies, 1816.

: Brit. Jour. Ven. Dis., 1925, 1. 58. quoted by Ironside.

: Berlin Klin Woch. XIV. 289.

: Ann. Med, Psych. 1882.

: Ann. Med. Psych. 1895.

: Brit. Jour. Ven. Dis. 1925. quoted by Ironside.

: Wien Med, Woch., 1909. IIX. 2124.

: Jahrb. f. Psych. 1905. $X X V .141$. 
63. Wagner-Jauregg.

54. Wagner-Tauregg.

65. Wagner-Jauregg.

66. Gerstmann,

67. Clark.

68. Board of Co
69. James, S.P.

70. Grant, A.R.

77. James, S.P.

72. Gerstmann, $\mathrm{J}$.

73. Kirschbaum.

74. Nonne, M.

75. Gerstmann, J.
: Wien Med. Woch., 1909. IIX. 2 I24.

: Psych. Neur. Woch. 191718. XX, 132.

: Wien. Med. Woch., 25 \& 27. 1921.

: Report of Board of Control. 1929, p. 24.

: Zeitschr f.d. ges Neurol in Psych. 1920. IX p: 328 1922. IXXIV. p. 242.

: Report of Board of Control, 1929.

: 1926. Ieague of Nations。 Malaria Commission Report.

: B.M.T. 1923, 11, 698.

: 1926. League of Nations. Malaria Commission Report.

- Die Malaria behandlung der progressiven paralyse.

: 1922. Zeit. f. d. ges. Neur u. Psych. IXXXV.635.

: 1925. Med. KIin. XXI. 1829.

: Die Malaria behandlung der progressiven paralyse.

76. Wethmar/ 
76. Wethmar.

77. Hermann \& Hlisnikowski.

78. Hopf.

79. Knights J.

80. Spierer.

81. Wendleberger.

82. Muller.
: Klin. Wchnschr. Leipzig, 1927, VI 1947.

: Med. Klin. Berlin 1928, XXIV, 1700.

: Munch. Med. Wchnschr. Munich, 1928, LXXV, 1755.

: Lab. \& Clin. Med. St. Louis, 1930, XV. 980 .

: Munch. med. Wchnschr. Munich, 1930, LXXVII, 1357.

: Wien. klin. Wchnschr, Vienna, 1930, XIIII, 932.

: Deutsche Ztschr. f. Nervenhik, Berlin, 1931 , CXX, 162 .

83. Engerth \& Stumpfl: Ztschr. f. d. ges. Neurol. u. Psychiat. Berlin, 1928, CXVIII, 256.

84. Puntigam.

: Med. Klin. Berlin, 1930, XXVI, pt. 2 122I.

85. Bravetta.

: Note $\theta$. Riv. di. Psychiat. Pesaro 1929, XVII, 233.

86. Wendlberger J. : Wien, Clin. Woch. 1930, July $2443, \mathrm{XXX}, 932$.

87. Spierer.

: Munich Med. Woch. 77, XXXII, $135 \%$.

88. Wagner Jauregg. : Wein. Med. Woch. No. 13.

89. Gerstmann.

: Die Malaria behandlung der progressiven paralyse.

90. Hermann.

: Med. KIIn. XXI, 395.

91. Unger.

: Med. KIIn. XXI, 1498.

92. F1scher \& Ascher.: Klin. Movats $f$. A ugenhlk IXXVI, 102, 1926

93. Hessberg. / 
93. Hessberg.

94. Ruge.

95. Lepine.

96. Mihaljeric \& Spengler.

97. Dattner \& Kanders.

98. Habermann \& Serefis.

99. Obarrio \& Petre.

100. Rudolf..

101. Kirschner \&c Van Loon.

102. Bercoritz.

103. Heinemann.

104. Lutrario.

105. Putigan.

106. Kyrle.

107. Bering.

108. Finger.
: (ibid) Fibr. 1930 p. 84.

: Zentrablat, F. Haut-in-Geschlechtskr, Berlin $192 \%$. $X X I V, I$.

: Journal de Med. de Iyon $1929,10,397$.

: Wein. Klin. Wchnschr. Vienna, 1929, 42, 1223.

Jahrb f. Psychiat. in

: Neurol, Loipzig. 1924, XIIII.

: Klin. Wehnschr. Berlin, $1928,7.1832$.

: Semana Med. Buenos Aires, $1931,35,1$.

: Therapeutic Malaria. Iondon, 1927.

: Klin. Wenschr, Berlin, 1924. 3,2001 .

: J.A.M.A. 1924, 82, 1713.

: Arch. f. Schiffs. In Tropen -Hyg. 1924, 28, 26, 187.

: Bull de I'officer Intermat. d'Hyg. pub. Paris 1928, 20, 719.

:Ztscht. f. d. ges. Neurol in Psychiat. 1931, 133, 223.

: Dermot Zyschr. 1922, 33, 313.

: Munich. med. Wehnschr. $1925,72,719$.

: Wein. Med. Wchnschr. 1926, $76,6$.

109. Memmeshejmer./ 